\title{
Bandwidth Enhanced MIMO antenna for LTE bands using Split Ring Resonators and stubs
}

\author{
A. Christina Josephine Malathi ${ }^{1}$, D. Thiripurasundari ${ }^{2}$ \\ ${ }^{1,2}$ School of Electronics and Communication Engineering, Vellore Institute of Technology, Vellore, India \\ *Corresponding Author, E-mail: achristina@vit.ac.in
}

\begin{abstract}
In this work, an array of circular patch antenna loaded with a partial split ring and a pair of stubs each with same dimensions, on each of the antenna is designed to operate in the LTE band with wide bandwidth. The split ring not only accounts for a newer operating band, but also tend to reduce the isolation and the stubs tends to increase the bandwidth which results in change by $44.92 \%$ compared to array of antennas without split rings. It has a compact substrate dimensions of $55 \times 30 \times 0.8 \mathrm{~mm}^{3}$ and ground of $55 \times 9$ $\mathrm{mm}^{2}$. The proposed antenna is simulated using high frequency structural simulator (HFSS) and fabricated. The measured results are in compliance with the simulated results. The proposed antenna find applications in LTE band $1,2,3,4,7,9,10,11,15,16,21,22,23,24,25,30,33,34$, $35,37,38,39,40,41,42,43 \mathrm{GHz}$ covering a broadband width of $2500 \mathrm{MHz}$.
\end{abstract}

\section{Introduction}

Microstrip patch antennas are used in modern communication systems due to their low cost, lightweight, and planar structure [1]. However, a microstrip patch antenna has some disadvantages. In the design of a microstrip patch array antenna, the radiating patch elements have to be placed in close proximity. It produces significant mutual coupling effect that deteriorates the antenna performance. The simplest solution to improve the antenna isolation is to increase the physical separation between the antennas [2, 3]. Although the isolation of the antennas becomes higher as the separation length is increased, the size of the antenna will subsequently be larger. However, the size of the antenna ground plane is limited in the practical micro strip patch antenna design. Particularly when the patch antenna is printed on high dielectric substrates, its radiation pattern is considerably affected by surface waves [4]. On a finite ground plane, surface waves propagate until they reach an edge where they are reflected back and diffracted by the edges. Multiple-input multiple- output (MIMO) antenna systems have emerged as an integral part of the new $4 \mathrm{G}$ wireless standards. They are a key enabling component to achieve high data rates for current and future needs of wireless communication services. Therefore, there is an increasing demand for making new MIMO antenna systems that are compact and compatible with user terminals and other wireless portable devices. For such systems, it is important to make antennas that have improved channel capacity, bandwidth, gain, and diversity performance [5]. These requirements make the design of MIMO antenna systems challenging. While designing compact antennas, antenna miniaturization techniques are used that can yield low antenna bandwidth, efficiency, and gain. Similarly, in a compact design, the antenna elements are placed close to each other, resulting in high correlation between the antenna elements and therefore poor diversity performance $[6,7]$. Thus, in the design of a MIMO antenna system, it is important to employ antenna miniaturization techniques that keep the antenna design simple and its compromise with the other antenna parameters is at a minimum.

In this article, we have reported the design of a compact $2 \times 1$ circular mimo antenna loaded with split ring and a pair of symmetrical stubs. The stub is responsible for widening up the bandwidth along the higher frequency range. The split ring plays a vital role in opening up the lower range of frequencies and also to create a wider stop band, so that, it filters a part of radiation [8]. On the whole, the antenna is designed at $2.5 \mathrm{GHz}$ for LTE band operation. A prototype of the proposed antenna is fabricated and measured to validate the simulated results. The paper is organized as follows. Section 2 discusses the design of antenna. Section 3 presents and associates the simulation and measured results and Section 4 concludes the paper. 


\section{Antenna Design}

The evolution of the proposed antenna is shown in Fig. 1. The main radiator is the circular patch which is on a $55 \times 30 \times 0.8 \mathrm{~mm}^{3}$ FR-4 substrate with relative permittivity, $\varepsilon_{\mathrm{r}}=4.4$ and loss tangent, $\delta=0.018$. The ground plane is $55 \times 9 \mathrm{~mm}^{2}$ printed on the back side of the substrate. The array is fed by a $15 \times 4 \mathrm{~mm}^{2}, 50 \Omega$ microstrip line.

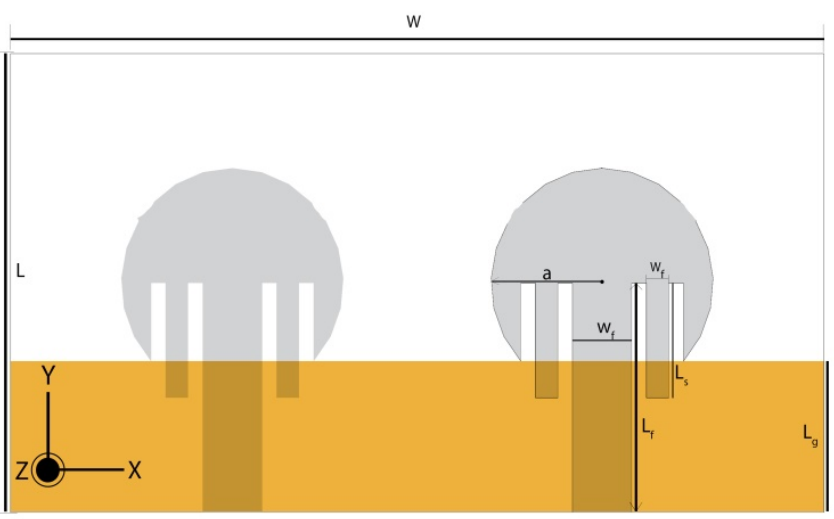

Figure 1: Evolution of proposed antenna

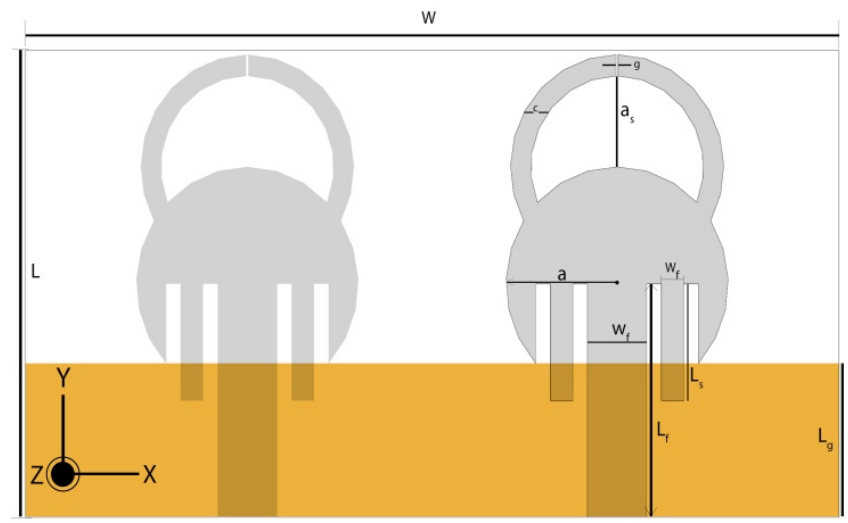

Figure 2: Proposed antenna

The Circular patch is designed using [9] Equation (1) and (2)

$$
\begin{gathered}
f_{r}=\frac{1.8142 * c}{4 \pi a_{e} \sqrt{\varepsilon_{r}}} \rightarrow(1) \\
a_{e}=a\left\{1+\frac{2 h}{\Pi a \varepsilon_{r}}\left[\ln \left(\frac{\Pi a}{2 h}\right)+1.7726\right]\right\}^{-1 / 2} \rightarrow(2)
\end{gathered}
$$

Where, $c$ is the velocity of light and $a_{e}$ is the effective radius of the circular patch, ' $a$ ' is the radius of the circular patch,
' $h$ ' is the height of the substrate, and $f_{\mathrm{r}}$ is the resonant frequency. The front view and back view of the fabricated antenna is shown in Fig 3. (a) and Fig 3. (b).

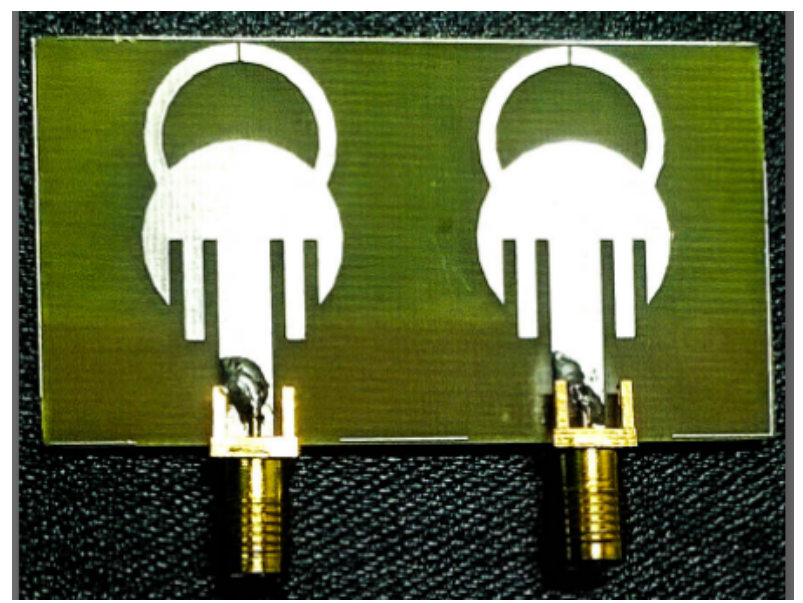

Figure 3 (a): Fabricated Antenna (Front View)

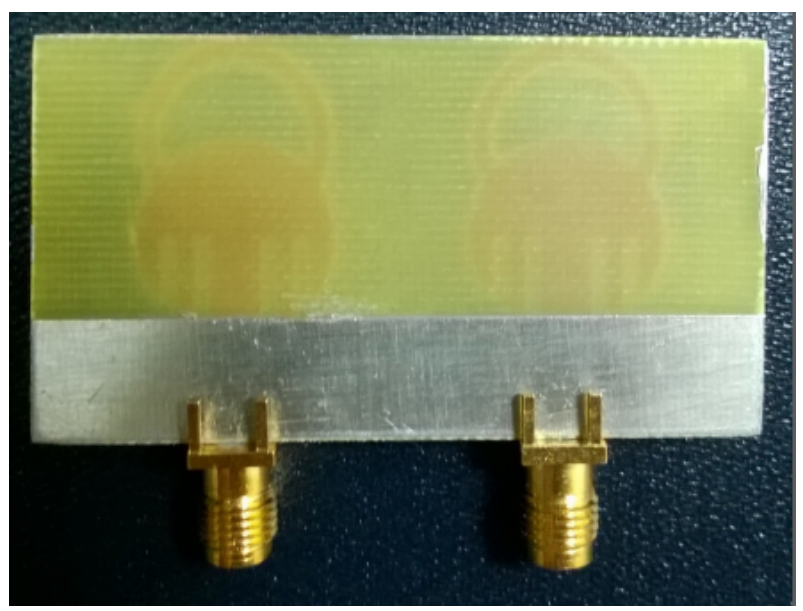

Figure 3 (b): Fabricated Antenna (Back View)

The patch radius is $\mathrm{a}=7.5 \mathrm{~mm}$ providing a $2.5 \mathrm{GHz}$ resonating frequency. In Fig. 2 , a $\lambda_{\mathrm{g}} / 2$ circular split ring is loaded partially on the top of the each monopole yielding an even wider bandwidth. The distance is chosen to be maximum and equal to the radius of the monopole, which is $7.5 \mathrm{~mm}$. The radius of the split ring plays a critical role in determining the lower limit of bandwidth. An optimal radius of $5.85 \mathrm{~mm}$ is chosen for the split ring. The width of the split ring is $1.35 \mathrm{~mm}$. Then, as shown in Fig.1, a pair of symmetrical stubs of dimension $7.5 \times 1.5 \mathrm{~mm}^{2}$ is loaded on either side of the micro strip feed which are self-resonant at $\lambda_{\mathrm{g}} / 4$ when placed closer to the feed. Placing the stubs at a distance of $1 \mathrm{~mm}$ from the feed increased the bandwidth. The dimension specifications are shown in Table 1 below, 
Table 1: Dimension specification

\begin{tabular}{cccc}
\hline Parameter & $\begin{array}{c}\text { Dimensions } \\
(\mathrm{mm})\end{array}$ & Parameter & $\begin{array}{c}\text { Dimensions } \\
(\mathrm{mm})\end{array}$ \\
\hline $\mathrm{L}$ & 30 & $\mathrm{~W}$ & 55 \\
$\mathrm{~L}_{\mathrm{g}}$ & 9 & $\mathrm{~h}$ & 0.5 \\
$\mathrm{~L}_{\mathrm{f}}$ & 15 & $\mathrm{~W}_{\mathrm{f}}$ & 4 \\
$\mathrm{~L}_{\mathrm{s}}$ & 7.5 & $\mathrm{~W}_{\mathrm{s}}$ & 1.5 \\
$\mathrm{a}$ & 7.5 & $\mathrm{a}_{\mathrm{s}}$ & 5.85 \\
$\mathrm{c}$ & 1.35 & $\mathrm{~g}$ & 0.15 \\
\hline
\end{tabular}

\section{Results and Discussion}

The simulations are performed using the Finite Element Method-based commercial software, High Frequency Structure Simulator. Comparison of simulated reflection coefficients and transmission coefficient of the two configurations of Fig. 1 and Fig. 2 is shown in Fig. 4 and Fig.5. The antenna with split ring has a wider band resonance from $1.12 \mathrm{GHz}$ to $3.62 \mathrm{GHz}$ yielding a bandwidth of $2500 \mathrm{MHz}$ with return loss of $-26 \mathrm{~dB}$ and isolation of $15.8 \mathrm{~dB}$. The fabricated antenna covers a bandwidth of 1 $\mathrm{GHz}$ to $3.8 \mathrm{GHz}$ with return loss of $-25 \mathrm{~dB}$ and isolation of $14 \mathrm{~dB}$. A comparative plot of simulated and measured return loss and isolation are shown in Fig. 6 and Fig. 7.

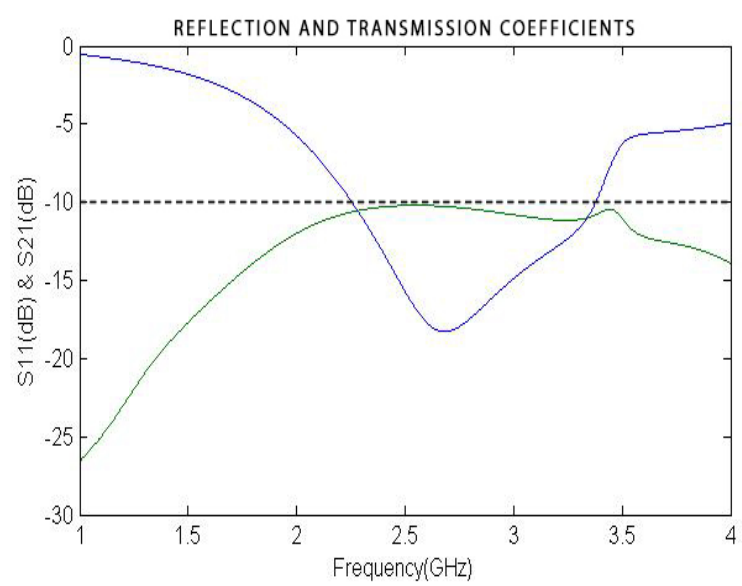

Figure 4: Simulated Reflection and transmission Coefficients of antenna without Split Ring

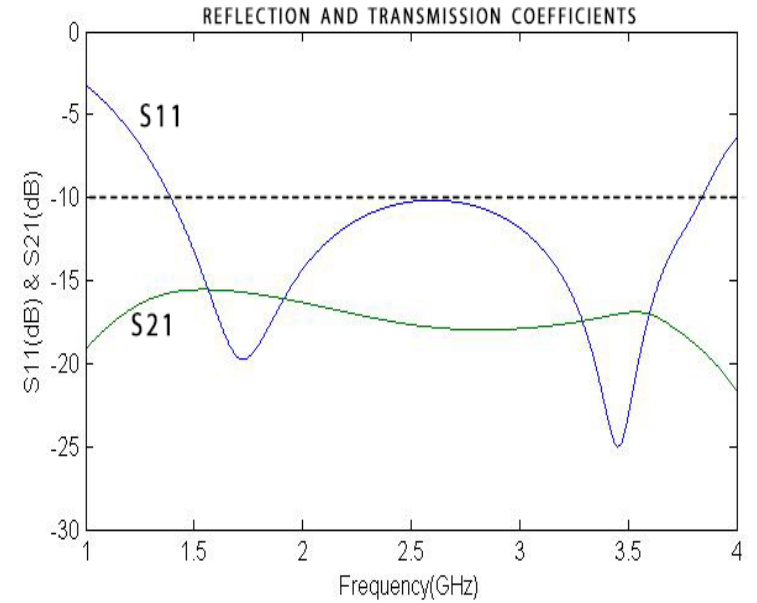

Figure 5: Simulated Reflection and transmission coefficient of antenna with split ring resonators.

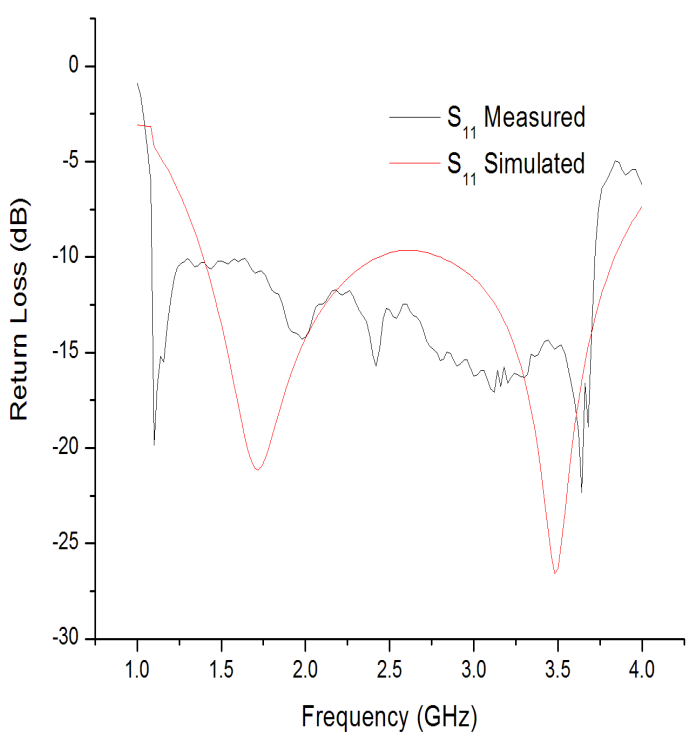

Figure 6: Comparison of simulated and measured Return Loss 


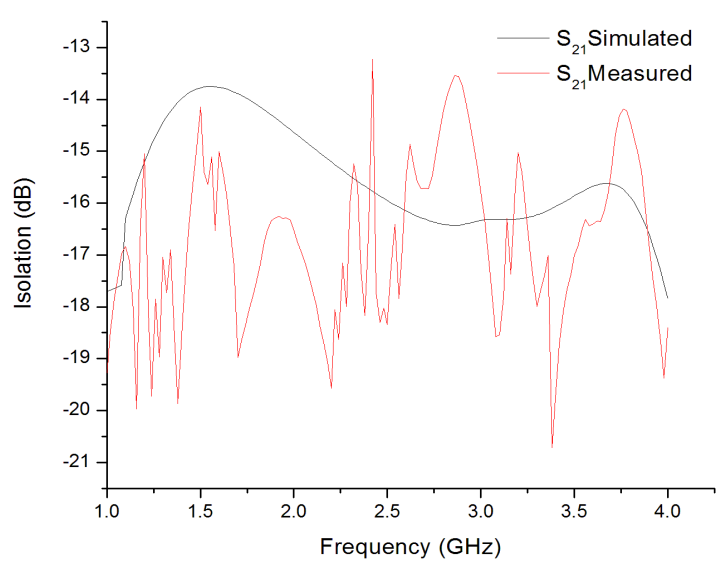

Figure 7: Comparison of simulated and measured Isolation $(\mathrm{dB})$

Total Active Reflection Coefficient (TARC) is defined as the available power radiated from the antenna and is given by Equation (3). The TARC graph shown in Fig.8 shows the effective response of the antennas with radiated power [10].

$$
\Gamma_{a}^{t}=\sqrt{\frac{\left(\left(\left|S_{11}+S_{12} e^{j \theta}\right|^{2}\right)+\left(\left|S_{21}+S_{22} e^{j \theta}\right|^{2}\right)\right)}{2}} \rightarrow \text { (3) }
$$

Here $\theta$ is the phase of the feed and $S_{x x}, S_{x y}$ are the $S$ parameters associated with the antenna. The TARC is a real number between zero and one. When the value of the TARC is equal to zero, all the delivered power is radiated and when it is equal to one, all the delivered power is either reflected back to sources or goes to the other ports. Here the optimized TARC value is obtained to be 0.0003 at $3.35 \mathrm{GHz}$.

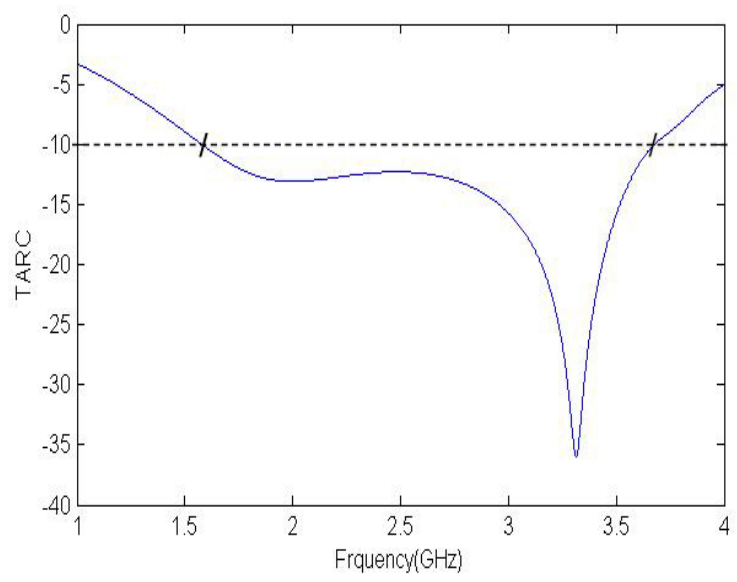

Figure 8: TARC
Envelope correlation coefficient (ECC) is the measure that describes how the communication channels are isolated from each other. Since the diversity performance of MIMO antennas is directly related to the minimum coupling between individual antenna elements, the isolation between the elements of the proposed antenna was measured. It is defined as the square roots of the ratio of the sum of the power available at all the ports minus the radiated power to the total available power [11]. This mainly deals with the radiation pattern of the antenna [12] which is defined by Equation (4) as

$$
\left|\rho_{(i, j)}\right|^{2}=\left|\frac{S_{i i}^{*} S_{i j}+S_{j i}^{*} S_{j j}}{\left|\left(1-\left|S_{i i}\right|^{2}-\left|S_{j i}\right|^{2}\right)\left(1-\left|S_{j j}\right|^{2}-\left|S_{i j}\right|^{2}\right)\right|^{1 / 2}}\right|^{2} \rightarrow(4)
$$

Where $\rho_{\mathrm{ij}}$ is the correlation coefficient, $\left|\rho_{\mathrm{ij}}\right|^{2}$ is the envelop correlation coefficient, $\mathrm{S}_{\mathrm{ij}}$ is the coupling factor between the $i^{\text {th }}$ and $j^{\text {th }}$ elements. Using this formula we need to know only the S-parameters and the ECC is calculated and shown in Fig.9. The ECC is 0.005 which is within the limits specified by LTE standard.

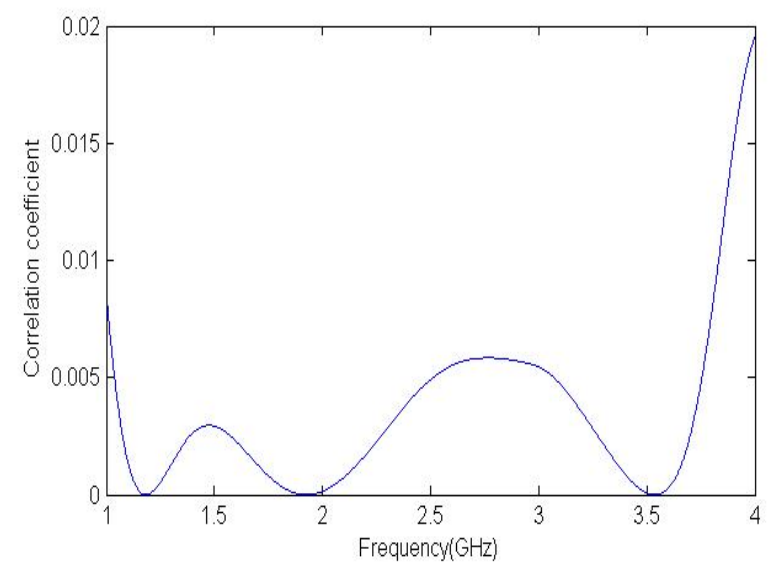

Figure 9: Envelope Correlation co-efficient

\section{Conclusion}

A compact broadband antenna loaded with stubs and split ring, suitable for LTE band 1, 2, 3, 4, 7, 9, 10, 11, 15, 16, 21, $22,23,24,25,30,33,34,35,37,38,39,40,41,42,43 \mathrm{GHz}$ application is presented in this article. Analysis of split ring and the effect of stubs in obtaining wider bandwidth, isolation are discussed. The proposed antenna is fabricated and the performances are measured. Simulation and measurement results are found to be in good agreement, proving the antenna to be a good choice for practical implementation. 


\section{References}

[1] K.L. Wong, Compact and broadband microstrip antennas, Wiley, New York, 2002.

[2] C.K. Aanandan, P. Mohanan, and K.G. Nair, "Broad-band gap coupled microstrip antenna", IEEE Trans Antennas Propag, 38, 1581-1586, 1990.

[3] M.-C. Pan and K.-L. Wong, "A broadband slotloaded trapezoid microstrip antenna", Microwave Opt Technol Lett , 24 ,16-19, 2000.

[4] F. Yang, X.X. Zhang, X. Ye, and Y. Rahmat-Samii, "Wide-band Eshaped patch antennas for wireless communications", IEEE Trans Antennas Propag, 49, 1094-1100, 2001.

[5] J.-S. Sun and S.-Y. Huang, "Broadband printed planar monople antenna for wireless terminal devices applications", Microwave Opt Technol Lett $55,79-82,2013$.

[6] J.-C. Diot, T. Tarati, B. Cadilhon, B. Cassany, P. Modin, and E. Merle, "Wideband patch antenna for HPM applications", IEEE Trans Plasma Sci, 39, 1446-1454, 2011.

[7] M.-C. Pan and K.-L. Wong, "A broadband slotloaded trapezoid microstrip antenna", Microwave Opt Technol Lett 24, 16-19, 2000.

[8] K.-L. Wong and W.-H. Hsu, "A broad-band rectangular patch antenna with a pair of wide slits", IEEE Trans Antennas Propag, 49, 1345-1347, 2001.

[9] C.A. Balanis, Microstrip antennas, "In: Antenna theory analysis and design", Wiley, Hoboken, New Jersey, 2005.

[10] M. Manteghi and Y.Rahmat-Samii, "Multiport characteristics of a wideband cavity backed annular patch antenna for multi polarization operations," IEEE Transactions on Antennas and Propagation, vol.53, no.1, pp. 466- 474, 2005.

[11] S. Su, C. Lee and F. Chang, "Printed MIMOAntenna System Using Neutralization-Line Technique for Wireless USB-Dongle Applications", IEEE Transaction on Antennas and Propagation, Vol. 60, No. 2, pp. 456-463, 2012.

[12] S. Blanch, J. Romeu, I. Corbella, "Exact representation of antenna system diversity performance from input parameter description", IET Electronic Letters, Vol. 39, No. 9, 707-707 May, 2003. 